\title{
How to use Google street view for a time-lapse data collection methodology: potential uses for retailing
}

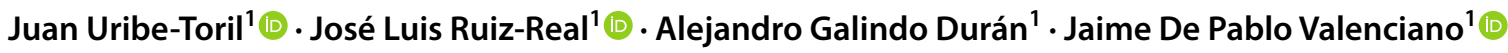

Received: 9 May 2021 / Accepted: 26 October 2021 / Published online: 6 November 2021

(c) The Author(s) 2021

\begin{abstract}
Finding the optimal location is a relevant strategic decision for retailers. The classic theories of retail location offer complementary perspectives, and later models include new variables, although they present methodological problems, these methodologies are static in time. Google Street View (GSV) allows extending the analysis of predictive models to different fields by a time-lapse collection data offering new opportunities to research and providing dynamic information. The development of a customized methodology, incorporating the time-lapse technique for practical applications, is the main contribution of this research, since there is almost no research on this topic.
\end{abstract}

Keywords Methodology $\cdot$ Store location $\cdot$ Retailing $\cdot$ Time-lapse $\cdot$ GSV

\section{Introduction}

This article aims to show a new methodology for data collection based on Google Street View (GSV) using the timelapse function, which allows planning and decision-making based on direct observation of a certain environment, generally urban. As an example of the development of the data collection methodology, its potential use will be applied to the location of retail stores.

To study the state of the art regarding the existence or not of a similar methodology prior to the publication of this article, we have carried out a systematic study based on bibliometric techniques for literature review, mainly through the Web Science (WoS) Core Collection database and as an accessory and to verify the validity of the search, the Scopus database.

Juan Uribe-Toril

juribe@ual.es

José Luis Ruiz-Real

jlruizreal@ual.es

Alejandro Galindo Durán

alejandro@galindoduran.com

Jaime De Pablo Valenciano

jdepablo@ual.es

1 Faculty of Economics and Business, University of Almeria, Ctra. De Sacramento, s/n, 04120 Almería, Spain
"Google Street View" has been used as a keyword since in this way it includes similar formulations such as Streetview or Street-view. Following this initial step, a process of data cleansing is performed. The databases contain different types of documents that contain the three words in the title, abstract, keywords included by the author himself or Keywords Plus.

The total number of documents retrieved in the 12-year time range (2009-2020) is 458 , a number very similar to that of Scopus, with 546 documents retrieved for the same period.

For our study, we delimited the number of publications by eliminating certain types of documents, either because they are not complete investigations, or because they are reviews that do not develop new methodologies. Thus, the following document types were excluded: proceedings paper (142), literature reviews (7), editorials (5), and poetry (1). On the other hand, we retain research areas, categories, languages and other search criteria, resulting in 303 documents. The results are essentially repeated in Scopus with 301 documents.

By analyzing the documents through their summaries and / or reading the complete texts, we can highlight the following characteristics:

- In all cases, the treatment of the GSV results is static over time and the temporal correlation is not used. 
- In most cases, it has been used as an alternative or comparative to traditional physical exploration.

- No document has been found that focuses on GSV as its own methodology, but rather always as part of previous methodologies.

Following the traditional structure of bibliometric analysis and with reference to their evolution over time, the most prolific authors and journals, as well as the main categories and areas of knowledge, are analyzed in order to obtain an overview of the state of the art.

Regarding the temporal evolution of these articles, from 2010 to 2019, the number of articles that include GSV has multiplied by 10 , evidence that it is a tool whose utility has spread to academia.

With regards to the scientific production by authors, we can highlight Xiaojiang Li and Carlo Ratti, from the Massachusetts Institute of Technology (MIT), who, with 17 registered documents, are the researchers who have most focused their studies on GSV as a methodology. Their work "show a methodology using GSV panoramic images to estimate and predict the appearance of sun glare.

However, it is the article "Where, When, Why, and For Whom Do Residential Contexts Matter? Moving Away from the Dichotomous Understanding of Neighborhood Effects", by Professors Sharkey and Faber, which has received the greatest number of citations (207) (Sharkey and Faber 2014). While this article does not address the use of GSV directly, it is widely used in its bibliography. The article titled "Using Google Street View to Audit Neighborhood Environments" (Rundle et al. 2011), with 203 citations, is the most cited.

The five main areas of knowledge, according to the WoS classification system, are Public Environmental Occupational Health (58); Geography (42), Urban Studies (35); Environmental Studies (30) and Physical Geography (26), practically coinciding with the research areas of the documents studied. Similar results are obtained when applied to the searches on Scopus.

To confirm the previous analysis carried out using WoS and Scopus, the search was expanded to Google Scholar, finding 13,300 results. This tool does not allow effective selection and refinement of results. However, the search for documents that contained "Google Street View" in the document title yielded 244 results, consistent with the results obtained with the other databases, thus confirming their validity.

As the design of the new methodology will fundamentally be used for urban elements, we have analyzed the 35 documents in the Urban Studies knowledge area and the 7 in Economics (Table 1).

To find out if similar methodologies exist, the following criteria have been considered:
- The object of study: investigations that focus on commercial premises or on building typologies, or that are related to the practical application developed for the new methodology.

- Whether the use of the GSV images has been static (photographs with a single reference year), or dynamic (the temporary functionality has been used).

- Whether the use of GSV is part of a new technique or development of a methodology.

Ewing and Clemente (2013) present an interesting analysis of the intangible elements of cities, studying the case of New York. Similarly, the analysis by Monteiro and Turczyn (2018) of Google Earth and GSV images, complemented by street level observations and photographs, adapts them to the categories of pattern identification in metropolitan territories.

The study by Lee and Talen (2014), in turn, contributes to the literature on walkability measurement by proposing a hybrid auditing method that combines a GIS-based approach with GSV.

Hipp et al. (2017) propose a dynamic application similar to that of Grubesic et al. (2018). In the case of the former, their study does not use GSV images but rather employs data obtained from images shot every $30 \mathrm{~min}$ by surveillance cameras in order to look for patterns of physical activity. In the case of the latter, their study raises the issue of frequency of images as an added difficulty of the study, since temporality is given by the use of two different tools, Google and Microsoft (Bing) showing multi-year temporary gaps.

In 2019, two methodological investigations are published. While Zhang et al. rely on open data to measure the quality of life and health of neighborhoods in Atlanta (USA), and use GSV as a data source; Middel et al. use GSV imagery to assess urban form and composition of cities from a humancentric perspective.

As can be seen in Table 1, none of the references study the three variables considered in this study at the same time. That is, none of them consider urban planning or building as an object of study, development of a new methodology, and that it be a temporarily dynamic analysis in the same study.

\section{Retailing location choice theories}

The location of a store is one of the most relevant strategic decisions for retailers. Kuo et al. (2002) claim that choosing a location is one of the most critical decisions of a small retail establishment. Moreover, the choice of location may be a determining factor for the success or failure of a retailer (Scarborough and Zimmerer 2004). Jaravaza and Chitando (2013) study the role of store location as an influencing factor in customers' store choice, furthermore, Ilbahar 
Table 1 Literature on GSV in the fields of Urban Studies and Economics. Source: own compilation

\begin{tabular}{|c|c|c|c|c|}
\hline Authors and year & Main object of study & Knowledge area & Use of GSV & $\begin{array}{l}\text { Dynamic } \\
\text { (Timelap)/ } \\
\text { Static }\end{array}$ \\
\hline Ewing and Clemente (2013) & Urban Design & Urban studies & Method & Static \\
\hline Guo (2013b) & Parking & & Tool & \\
\hline Gordon and Janzen (2013) & Suburbs & & & \\
\hline Guo (2013a) & Parking & Economy & & \\
\hline Hanson et al. (2013) & Transport & & & \\
\hline Lee and Talen (2014) & Walkable Environments & Urban Studies & Method & Static \\
\hline Li et al. $(2015 a, b)(a)$ & Vegetation & Urban Studies & Tool & Static \\
\hline Li et al. $(2015 a, b)(b)$ & Vegetation & & & \\
\hline Sedano (2016) & Advertising & & & \\
\hline Li et al. (2016) & Vegetation & Urban Studies & Tool & Static \\
\hline Mygind et al. (2016) & Vegetation & & & \\
\hline Moniruzzaman and Paez (2016) & Walkable Environments & Economy & & \\
\hline Hipp et al. (2017) & Physical Activity & Urban Studies & Method & Dynamic \\
\hline Berland and Lange (2017) & Vegetation & & Tool & Static \\
\hline Goodspeed (2017) & Walkable Environments & & & \\
\hline Seiferling et al. (2017) & Vegetation & & & \\
\hline Grubesic et al. (2018) & Drones & Urban Studies & Tool & Dynamic \\
\hline Freemark (2018) & Building & & & Static \\
\hline Li and Ratti (2018) & Vegetation & & & \\
\hline Li et al. (2018) & Vegetation & & & \\
\hline Monteiro and Turczyn (2018) & Urban Spaces & & & \\
\hline Rigolon et al. (2018) & Vegetation & & & \\
\hline Ruggeri et al. (2018) & Livability & & & \\
\hline Zhang et al. (2018) & Urban Objects & & & \\
\hline Chen and Sekar (2018) & Travel & Economy & & \\
\hline Glaeser et al. (2018) & Big Data & & & \\
\hline Shatu and Yigitcanlar (2018) & Walkable Environments & & & \\
\hline Middel et al. (2019) & Metrics & Urban Studies & Method & Static \\
\hline Foster and Newell (2019) & Footpaths & & Tool & \\
\hline Hong et al. (2019) & Vegetation & & & \\
\hline Lakhotia et al. (2019) & Bus-stops & & & \\
\hline Li and Ratti (2019) & Pollution & & & \\
\hline Li et al (2019) & Pollution & & & \\
\hline Lu et al. (2019) & Cycling & & & \\
\hline Lu (2019) & Vegetation & & & \\
\hline Wang et al. (2019) & Building & & & \\
\hline Ye et al. (2019) & Vegetation & & & \\
\hline Zhang et al. (2019) & Livability & & & \\
\hline Tanas et al. (2019) & Building & Economy & & \\
\hline Nesse and Airt (2020) & Streetscapes & Urban Studies & Method & Dynamic \\
\hline Gobster et al. (2020) & Stewardship programs & & Tool & Static \\
\hline Tang et al. (2020) & Greenways & & & \\
\hline
\end{tabular}

and Kahraman (2018) state that retail store selection is an important decision for both customers and retailers since it is directly linked to customer satisfaction and retailers' profit. Given the extensive and multidisciplinary array of literature on the issue of store site selection (Nwogugu 2006), there exists a variety of ways to measure the "ideal location" for commercial establishments.

The three classic theories of retail location propose different ways of measuring the potential of commercial locations. The Principle of minimum differentiation (Hotelling 1929), argues that the most important factor is the relative 
proximity to other stores that offer similar goods or services; i.e., the tendency of businesses or products to cluster. Thus, proximity to competitors is considered more critical than proximity to customers. The other two classic theories of retail location focus on locational centrality. Thus, Spatial interaction theory (Reilly 1929) assumes that customers compensate for differences in store-specific product and service relative to the appeal of the place of purchase. This is the case, for example, of small convenience stores, which offer fewer standardized goods and services (Jones et al. 2003). Finally, Central place theory (Christaller 1933) focuses on the relationships between establishments of different sizes and relates their economic activities with the population. It states that its main function is to supply goods and services to the surrounding population. Geographical distance and transportation costs acquire a relevant role in the analysis, since demand for a good or service will decline with distance from the source of supply. Consequently, the locations closest to the customer's demand center guarantee a better positioning, in contrast to those located further away. This theory is considered to have significant predictive power, primarily for single-purpose shopping trips.

Since the appearance of GSV in 2007, new methodological opportunities appear for research on this topic. Wilson et al. (2012) show a precise and consistent agreement between observation field audits and image-based interpretation using GSV. Both academic research and companies have found that GSV offers an excellent opportunity for practical implementation and solving numerous problems.

However, GSV is not limited to the world of retailing as it offers many other possibilities for analysis and development of predictive models. Thus, Odgers et al. (2012) find it a reliable and cost effective tool for measuring both negative and positive features of local neighborhoods. Rundle et al. (2011) develop an exploratory study and find that GSV can be used to audit neighborhood environments. Wood and Reynolds (2012) study how retailers can take advantage of location research in order to better leverage geographical insights and assist in the realization of appropriate customer propositions and marketing strategies. Griew et al. (2013) develop a street audit tool using GSV to measure environmental supportiveness for physical activity. Hara et al. (2013) combine crowdsourcing and GSV to identify streetlevel accessibility problems in a city. Using GSV is a reliable method for assessing characteristics of the built environment (Kelly et al. 2012).

All these methodologies present a problem, they are static in time. In other words, they represent a "snapshot" of reality at a certain moment. Therefore, the time-lapse technique can be an excellent opportunity for a more thorough and in-depth analysis of retail store location. Time-lapse is a technique in which images are captured in sequence with a photo (or video) camera, which offers opportunities to obtain dynamic information about reality through its evolution over time. To our best understanding, there is almost no research incorporating the time-lapse technique for practical applications, and no study examines the retail sector. One of the few exceptions that includes dynamic analysis using GSV is Ilic et al. (2019) that present a Siamese convolutional neural network that automatically detects gentrification-like visual changes in temporal sequences of GSV images. Cohen et al. (2020) also use GSV images and their evolution over time to provide current and historical food retail data from 2007 to the present. The study shows how GSV can be used to analyze changing food environments that affect health.

For this paper, the main contributions are as follows: (1) this methodology allows researchers obtain data from a primary source, based on direct observation of a certain environment. (2) our dynamic time-lapse methodology will help to predict the potential popularity of locations over time, facilitating the process of decision making on retail store location, (3) this methodology may also help guide urban planners in designing commercial zones and transportation networks, to analyze spatial concentration of retailers, as well as study the factors affecting the rental value of residential property.

\section{Development of the methodology for data collection and practical application}

The methodology for collecting data for the analysis of commercial premises in a certain area begins with the selection of the area of influence.

It will be considered a radius of $150 \mathrm{~m}$ for the analysis. This distance is based on the investigations of Tan and Tan (1995); Nikilaos et al. (2011) or Ray (2017) who follow this same longitudinal criterion attending to visual, transport and visual impact elements. In the case of previously delimited areas (the intention is to study a street, district or singular area) it is recommended to create grids of approximately $900 \mathrm{~m}^{2}$.

Likewise, it is advisable to create a table with a list of all the streets affected, list the premises or buildings within that radius of action to later record the data, as shown in the diagram (Fig. 1).

It should be noted that GSV imagery allows us to access spatial and temporal data, only in those places and times where the technology was employed. In most cases, this data is available from 2008 onwards with an increasing number of images and data available for research.

The data collection scheme was carried out following the criteria of standardized graphic notation system, BPMN (Business Process Model and Notation). BPMN is aimed at process modeling and is one of the best organization 


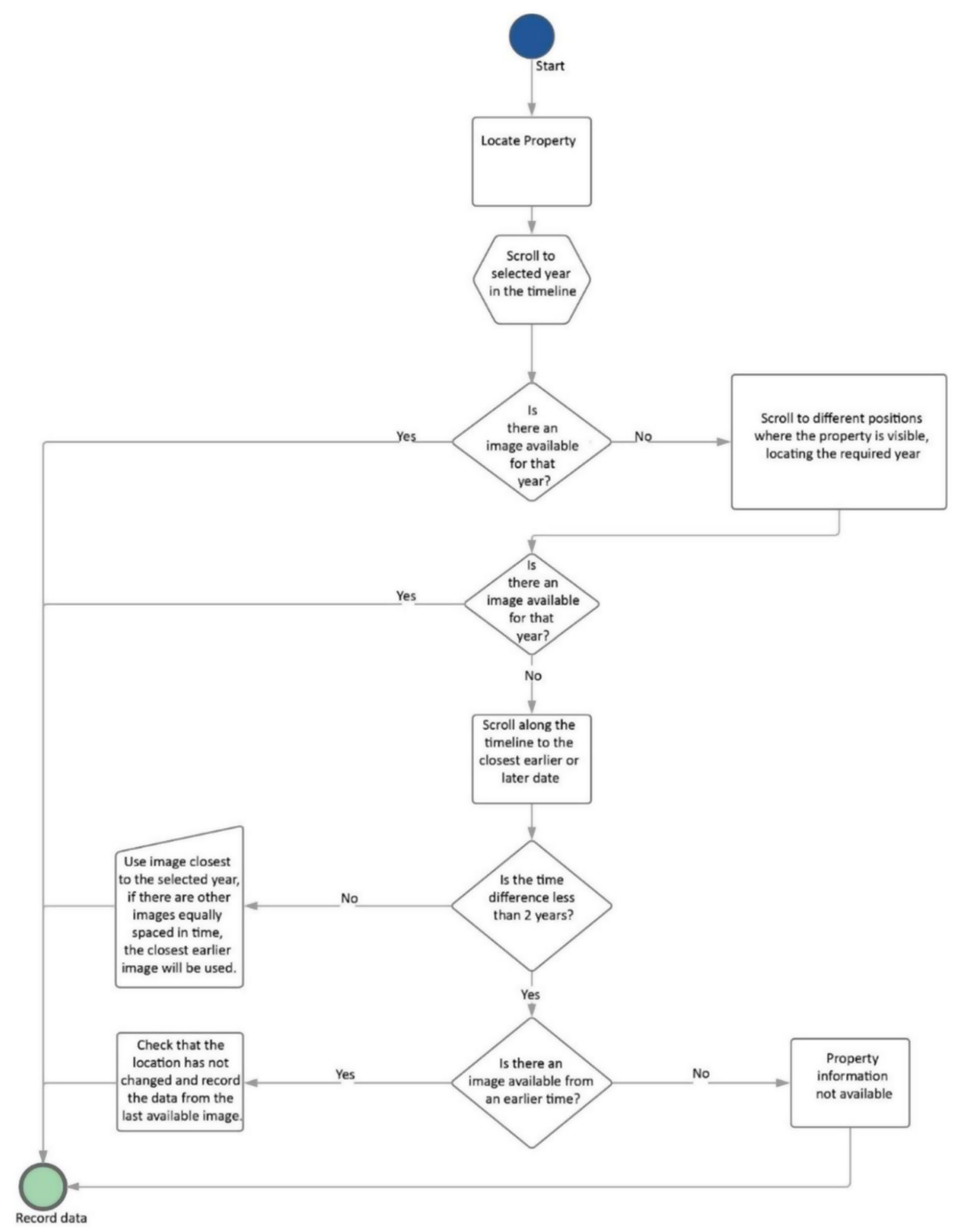

Fig. 1 Diagram for data collection in temporal variables in GSV. Source: own compilation 
Fig. 2 Selected property and its area of influence. Source: own compilation based on Google Maps (2019)

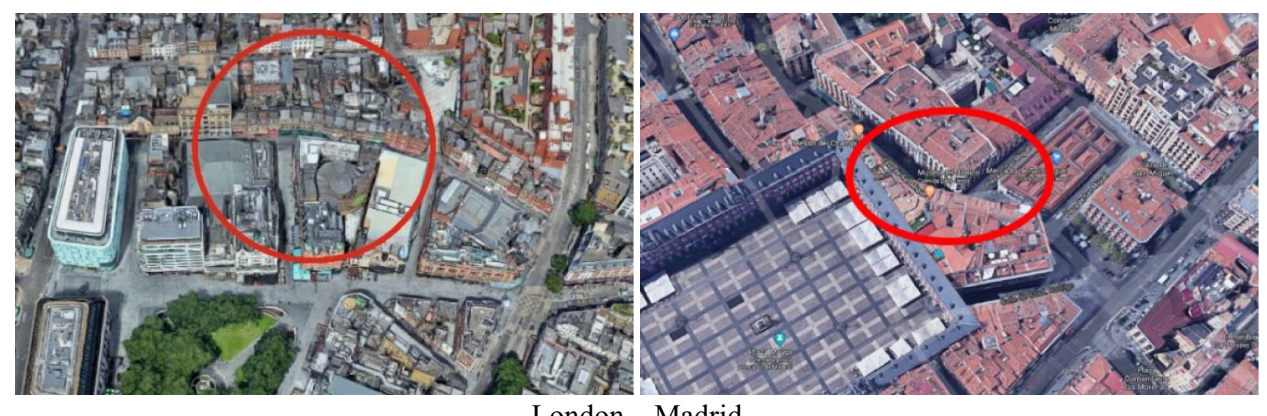

London - Madrid

systems to follow quality and productivity criteria (Chinosi and Trombetta 2012).

\section{Data considerations and treatment}

The possible scenarios regarding the availability (or not) of images in GSV in the year of study are the following:

(1) Image is available: the data of the variables for that year is recorded.

(2) No image is available for the year being studied:

(a) There is an image available within 2 years of the year being studied: the data of the closest image in time is considered. Should there be both an earlier and a later image available, the data from the earlier image will be used.

(b) There is at least one image with a time difference greater than 2 years: the data from the earlier year will be considered for the image analysis. If there is no earlier image available, the data record will state that there is no valid information.

(3) Image not available for any year: as no image was obtained, the data record will state "Property information not available".
One of the main advantages of the data collection methodology is that the researcher is free to select the variables that will be registered, as well as their classification.

In the case of the study of commercial premises, and by way of example, some of the variables that may be of interest and data that can be obtained about the property include: the economic activity carried out; external elements of the establishment; facade of the property; competitive analysis. Likewise, information about the urban environment can be collected.

By way of example, an analysis of a commercial area located in the center of Madrid (Spain) and London (UK) is carried out (Fig. 2). From the starting position, the steps and instructions laid out in the diagram will be followed, in order to make position shifts or make decisions about years where information was not available.

The starting point offers us a timeline with sufficient information (Fig. 3), although, as will be seen, in some years there was no available images. In this example, we will analyze the selected commercial property as the epicenter of the area for the period between 2008 and 2019 using four variables: commercial activity (type of business), commercial signage, the space surrounding the entrance and, finally, the total surface area of the sidewalk around the property. (Figs. 4 and 5).

Data such as those provided by this research, of a specific location in London and Madrid, simply as an example of the type of quantitative and qualitative information that this methodology can provide, allow you to have a very complete
Fig. 3 GSV timeline for selected property. Source: own compilation from GSV
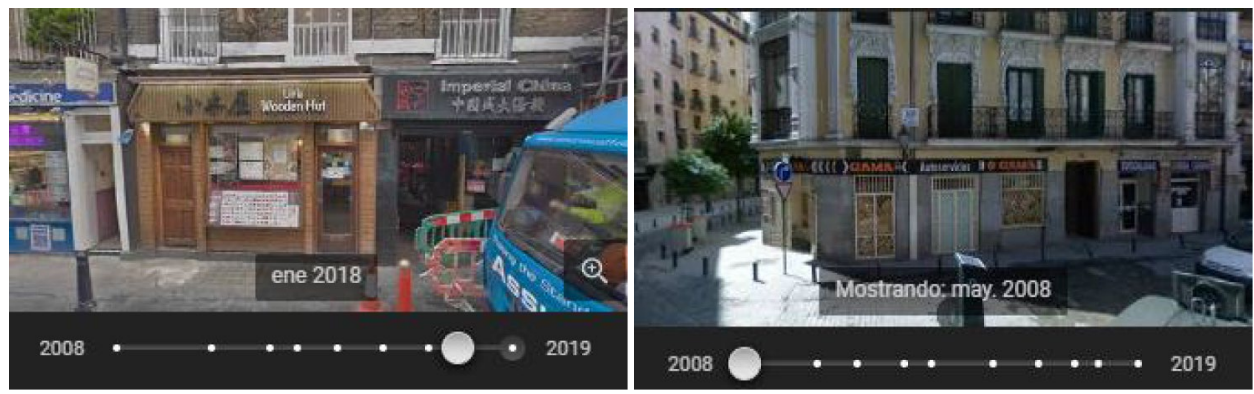

London - Madrid 
Fig. 4 Flow diagram, sequential images, and recorded data (2008-2013)

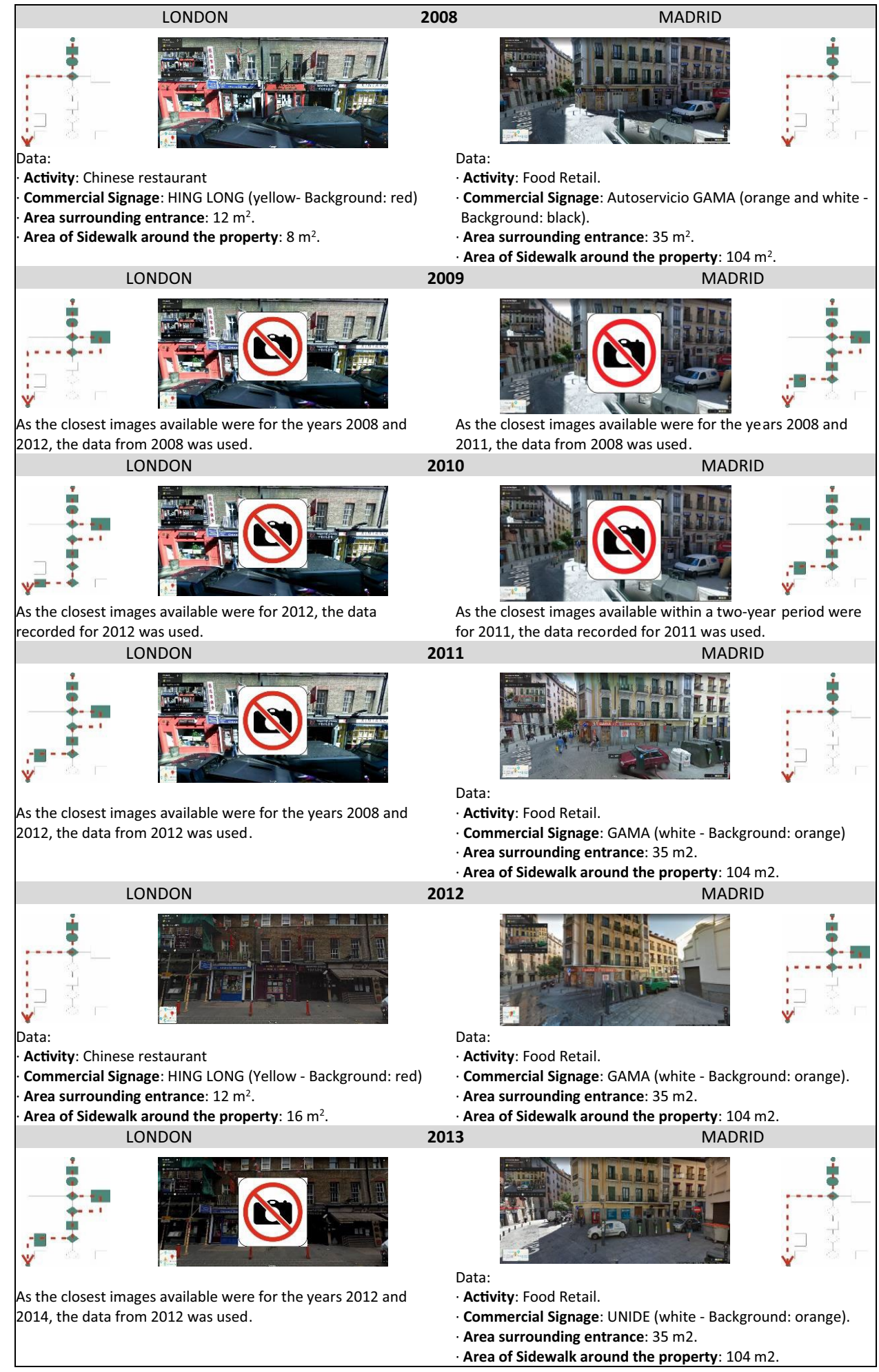

perspective of the location and movements that occur in the retailers and surrounding areas over time. It is not simply a matter of having information at a specific moment, but also allows us to observe the temporal evolution and analyze possible interactions between the different observed variables.
These data can be valued from different perspectives. Thus, for example, it offers useful information to be considered by the three classic theories of retail location, which propose different ways of measuring the potential of commercial locations. In this sense, for example, for the analysis 
Fig. 5 Flow diagram, sequential images, and recorded data (2014-2019). Source: own compilation

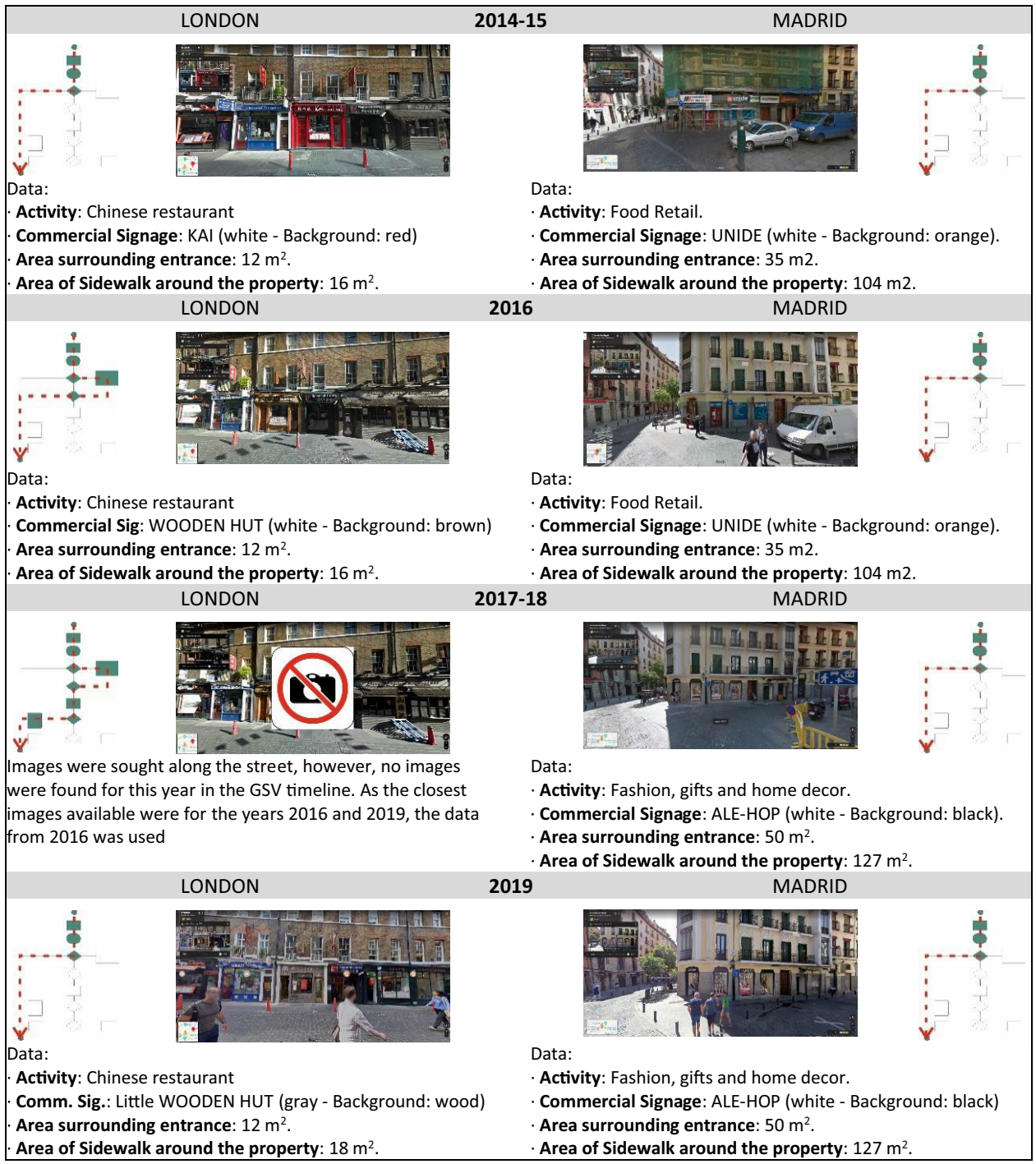

from the Principle of minimum differentiation, it is very important to know the openings and / or closings of the retailers around the central point of analysis. The density of competitors is key and knowing if there are retailers that offer similar goods or services can be decisive in the decision process.

\section{Conclusions and potential applications}

Store location is one of the most relevant strategic decisions for retailers since it may be a determining factor for success, even being directly linked to customer satisfaction. However, identifying the best locations is a complex decision for businesses to make. In this regard, there are different ways to evaluate store location. The three classic theories of retail location, Principle of minimum differentiation, Spatial interaction theory, and the Central place theory offer different and complementary perspectives. However, as described in this paper, many authors add different variables to these models when presenting some methodological problems inherent to them (e.g., the characteristics of the site is scarcely considered; the distance is over-emphasized; factors such as: the effect of site-specific operating costs, competing stores, or the economic value of customer's time on the location decision are not considered). In this way, different retail store location models are developed, with some research even focusing on specific retailers. In addition, since the development of GSV, new methodological opportunities appear for research which are not limited to retail stores, but rather extend the analysis and development of predictive models in different fields.

Nevertheless, these methodologies are static in time, representing the situation at a very specific moment. Therefore, time-lapse techniques offer new opportunities to research, favoring a deeper analysis, as well as obtaining dynamic 
information, thus observing the evolution over time of different variables that the researcher can personalize and adapt to their analysis. The development of a customized methodology, incorporating the time-lapse technique for practical applications, is the main contribution of this research, since to our best understanding, there is almost no research on this topic, and no study that examines the retail sector.

One of the most common problems that researchers face is the difficulty in finding available data, and on numerous occasions, the high cost of said data. In this article, we present a proposed methodology for obtaining spatio-temporal data through GSV as applied to commercial properties. New data that, when analyzed in combination with other methodologies, should broaden research horizons.

The data related to zoned commercial establishments aids the decision making process with regards to choosing the optimal location, competition studies, commercial gentrification movements or real estate investments, among others.

One of the advantages of the methodology applied to the study of commercial premises is that it allows the economic data of the establishments, which is easily identified (price of the land, rentals, turnover...), to be combined with other qualitative data (color of the facade, proximity to other establishments or width of sidewalk).

The primary data is a result of the direct observations of the researcher of the environment, and unusual in terms of research methodology, for different periods.

The data methodology shown allows the researcher the freedom to choose the desired time periods, and facilitates spatial autonomy, since it covers almost all of the urban centers.

As previously mentioned, GSV is a free tool, and consequently, the data preparation is free and remains in the hands of the researcher who can thus adapt their workload.

In addition to the obvious lines of research related to urban planning and construction, the possibilities offered for research are vast. As a guide, and without implying an exhaustive list of options, some possible uses in different areas of knowledge could be: archeology, to analyze the deterioration of buildings or exploitation of heritage; in health sciences in studies of different diseases and their relationship with neighborhoods or residential areas; on depopulation and its effects on rural municipalities; analysis of the consequences of climate change or even to compare some of the effects of the most recent pandemics in certain geographical areas.

As limiting factors of this tool, we must point out that GSV shows images of reality at a given moment, and sometimes it would be advisable to have shorter periods than are currently available. Moreover, the quality of the image may not be optimal and sometimes obstacles appear that prevent an adequate analysis.
Acknowledgements The authors greatly appreciate the reviewers who dedicated their considerable time and expertise to the article's rigorous peer-review process.

Funding Open Access funding provided thanks to the CRUE-CSIC agreement with Springer Nature. This research received no external funding.

Data availability Data sharing not applicable to this article as no datasets were generated or analysed during the current study.

\section{Declarations}

Conflict of interest The authors declare no conflict of interest.

Open Access This article is licensed under a Creative Commons Attribution 4.0 International License, which permits use, sharing, adaptation, distribution and reproduction in any medium or format, as long as you give appropriate credit to the original author(s) and the source, provide a link to the Creative Commons licence, and indicate if changes were made. The images or other third party material in this article are included in the article's Creative Commons licence, unless indicated otherwise in a credit line to the material. If material is not included in the article's Creative Commons licence and your intended use is not permitted by statutory regulation or exceeds the permitted use, you will need to obtain permission directly from the copyright holder. To view a copy of this licence, visit http://creativecommons.org/licenses/by/4.0/.

\section{References}

Berland A, Lange DA (2017) Google Street View shows promise for virtual street tree surveys. Urban for Urban Green 21:11-15

Chen RB, Sekar A (2018) Investigating the impact of Sense of Place on site visit frequency with non-motorized travel modes. J Transp Geogr 66:268-282

Chinosi M, Trombetta A (2012) BPMN: an introduction to the standard. Computer Standards \& Interfaces 34(1):124-134

Christaller W (1933) Central places in Southern Germany, (trans: Baskin C (1966). Prentice-Hall, Englewood Cliffs, NJ

Cohen N, Chrobok M, Caruso O (2020) Google-truthing to assess hot spots of food retail change: a repeat cross-sectional Street View of food environments in the Bronx, New York. Health Place. https:// doi.org/10.1016/j.healthplace.2020.102291

Ewing R, Clemente O (2013) Measuring urban design: metrics for liveable places / by Reid Ewing, Otto Clemente, 1st edn. 2013. https://doi.org/10.5822/978-1-61091-209-9

Freemark Y (2018) Challenges in the creation of mixed-use affordable housing: measuring and explaining its limited prevalence. Hous Policy Debate 28(6):1004-1021

Foster A, Newell JP (2019) Detroit's lines of desire: footpaths and vacant land in the Motor City. Landsc Urban Plan 189:260-273

Glaeser EL, Kominers SD, Luca M, Naik N (2018) Big data and big cities: the promises and limitations of improved measures of urban life. Econ Inq 56(1):114-137

Gobster PH, Rigolon A, Hadavi S, Stewart WP (2020) The conditioncare scale: a practical approach to monitoring progress in vacant lot stewardship programs. Landsc Urban Plan 203:103885

Goodspeed R (2017) Research note: An evaluation of the Elo algorithm for pairwise visual assessment surveys. Landsc Urban Plan 157:131-137

Gordon DL, Janzen M (2013) Suburban nation? Estimating the size of Canada's suburban population. J Arch Plan Res 3(3):197-220 
Griew P, Hillsdon M, Foster C, Coombes E, Jones A, Wilkinson P (2013) Developing and testing a street audit tool using Google Street View to measure environmental supportiveness for physical activity. Int J Behav Nutr Phys Act. https://doi.org/10.1186/ 1479-5868-10-103

Grubesic TH, Wallace D, Chamberlain AW, Nelson JR (2018) Using unmanned aerial systems (UAS) for remotely sensing physical disorder in neighborhoods. Landsc Urban Plan 169:148-159

Guo Z (2013a) Home parking convenience, household car usage, and implications to residential parking policies. Transp Policy 29:97-106

Guo Z (2013b) Residential street parking and car ownership: a study of households with off-street parking in the New York City region. J Am Plann Assoc 79(1):32-48

Hanson CS, Noland RB, Brown C (2013) The severity of pedestrian crashes: an analysis using Google Street View imagery. J Transp Geogr 33:42-53

Hara K, Le V, Froehlich J (2013) Combining crowdsourcing and Google street view to identify street-level accessibility problems. In: CHI'13 Proceedings of the SIGCHI Conference on Human Factors in Computing Systems, Paris, France, 631-640. Research Collection School of Information Systems. https://doi.org/10. $1145 / 2470654.2470744$

Hipp JA, Adlakha D, Eyler AA, Gernes R, Kargol A, Stylianou AH, Pless R (2017) Learning from outdoor webcams: surveillance of physical activity across environments. Seeing cities through big data. Springer, Cham, pp 471-490

Hong KY, Tsin PK, van den Bosch M, Brauer M, Henderson SB (2019) Urban greenness extracted from pedestrian video and its relationship with surrounding air temperatures. Urban for Urban Green 38:280-285

Hotelling H (1929) Stability in competition. Economic J 39(March):41-57

Ilbahar E, Kahraman C (2018) Retail store performance measurement using a novel interval-valued Pythagorean fuzzy WASPAS method. J Intell Fuzzy Syst 35(3):3835-3846. https://doi.org/10. 3233/JIFS-18730

Ilic L, Sawada M, Zarzelli A (2019) Deep mapping gentrification in a large Canadian city using deep learning and Google Street View. PLoS ONE 14(3):e0212814

Jaravaza DC, Chitando P (2013) The role of store location in influencing customers' store choice. J Emerg Trends Econ Manag Sci 4(3):302-307

Jones M, Mothersbaugh D, Beatty S (2003) The effects of locational convenience on customer repurchase intentions across service types. J Serv Mark 17(7):701-712

Kelly CM, Wilson JS, Baker EA, Miller DK, Schootman M (2012) Using Google Street View to audit the built environment: interrater reliability results. Ann Behav Med 45(1):108-112. https:// doi.org/10.1007/s12160-012-9419-9

Kuo RJ, Chi SC, Kao SS (2002) A decision support system for selecting convenience store location through integration of fuzzy AHP and artificial neural network. Comput Ind 47(2):199-214. https:// doi.org/10.1016/S0166-3615(01)00147-6

Lakhotia S, Rao KR, Tiwari G (2019) Accessibility of bus stops for Pedestrians in Delhi. J Urban Plan Develop 145(4):05019015

Lee S, Talen E (2014) Measuring walkability: a note on auditing methods. J Urban Des 19(3):368-388. https://doi.org/10.1080/13574 809.2014.890040

Li X, Cai BY, Qiu W, Zhao J, Ratti C (2019) A novel method for predicting and mapping the occurrence of sun glare using Google Street View. Transp Res C Emerg Technol 106:132-144

Li X, Ratti C (2018) Mapping the spatial distribution of shade provision of street trees in Boston using Google Street View panoramas. Urban for Urban Green 31:109-119
Li X, Ratti C (2019) Mapping the spatio-temporal distribution of solar radiation within street canyons of Boston using Google Street View panoramas and building height model. Landsc Urban Plan 191:103387

Li X, Ratti C, Seiferling I (2018) Quantifying the shade provision of street trees in urban landscape: a case study in Boston, USA, using Google Street View. Landsc Urban Plan 169:81-91

Li X, Zhang C, Li W, Ricard R, Meng Q, Zhang W (2015a) Assessing street-level urban greenery using Google Street View and a modified green view index. Urban for Urban Green 14(3):675-685

Li X, Zhang C, Li W, Kuzovkina YA, Weiner D (2015b) Who lives in greener neighborhoods? The distribution of street greenery and its association with residents' socioeconomic conditions in Hartford, Connecticut, USA. Urban for Urban Green 14(4):751-759

Li X, Zhang C, Li W, Kuzovkina YA (2016) Environmental inequities in terms of different types of urban greenery in Hartford, Connecticut. Urban for Urban Green 18:163-172

Lu Y (2019) Using Google Street View to investigate the association between street greenery and physical activity. Landsc Urban Plan 191:103435

Lu Y, Yang Y, Sun G, Gou Z (2019) Associations between overheadview and eye-level urban greenness and cycling behaviors. Cities 88:10-18

Middel A, Lukasczyk J, Zakrzewski S, Arnold M, Maciejewski R (2019) Urban form and composition of street canyons: A humancentric big data and deep learning approach. Landsc Urban Plan 183:122-132

Moniruzzaman M, Páez A (2016) An investigation of the attributes of walkable environments from the perspective of seniors in Montreal. J Transp Geogr 51:85-96

Monteiro EZ, Turczyn DT (2018) The five categories of Solà-Morales as a legacy for reading the urban landscape. ACE 12(36):73-90

Mygind L, Bentsen P, Badland H, Edwards N, Hooper P, Villanueva K (2016) Public open space desktop auditing tool-Establishing appropriateness for use in Australian regional and urban settings. Urban for Urban Green 20:65-70

Nesse K, Airt L (2020) Google Street View as a replacement for inperson street surveys: Meta-analysis of findings from evaluations. J Urban Plan Develop 146(2):04020013

Nikilaos K, Dimitra V, Agapi X (2011) Real estate values and environment: a case study on the effect of the environment on residential real estate values. Int J Acad Res 3(1):861-868

Nwogugu M (2006) Site selection in the US retailing industry. Appl Math Comput 182(2):1725-1734. https://doi.org/10.1016/j.amc. 2005.12.050

Odgers CL, Caspi A, Bates CJ, Sampson RJ, Moffitt TE (2012) Systematic social observation of children's neighborhoods using Google Street View: a reliable and cost-effective method. J Child Psychol Psychiatry 53(10):1009-1017. https://doi.org/10.1111/j. 1469-7610.2012.02565.x

Ray R (2017) Open for business? Effects of Los Angeles Metro Rail construction on adjacent businesses. J Transp Land Use 10(1):725-742

Reilly WJ (1929) Methods for the study of retail relationships. University of Texas, Austin

Rigolon A, Toker Z, Gasparian N (2018) Who has more walkable routes to parks? An environmental justice study of Safe Routes to Parks in neighborhoods of Los Angeles. J Urban Aff 40(4):576-591

Ruggeri D, Harvey C, Bosselmann P (2018) Perceiving the livable city: cross-cultural lessons on virtual and field experiences of urban environments. J Am Plan Assoc 84(3-4):250-262

Rundle AG, Bader MD, Richards CA, Neckerman KM, Teitler JO (2011) Using Google Street View to audit neighborhood environments. Am J Prev Med 40(1):94-100 
Scarborough N, Zimmerer T (2004) Effective small business management. Prentice Hall, Upper Saddle River, NJ

Sedano E (2016) 'Sensor'ship and spatial data quality. Urban Planning 1(2):75-87

Seiferling I, Naik N, Ratti C, Proulx R (2017) Green streets- Quantifying and mapping urban trees with street-level imagery and computer vision. Landsc Urban Plan 165:93-101

Sharkey P, Faber JW (2014) Where, when, why, and for whom do residential contexts matter? Moving away from the dichotomous understanding of neighborhood effects. Ann Rev Sociol 40:559-579

Shatu F, Yigitcanlar T (2018) Development and validity of a virtual street walkability audit tool for pedestrian route choice analysisSWATCH. J Transp Geogr 70:148-160

Tan SY, Tan HS (1995) A theory for propagation path-loss characteristics in a city-street grid. IEEE Trans Electromagn Compat 37(3):333-342

Tanaś J, Trojanek M, Trojanek R (2019) Seniors' revealed preferences in the housing market in Poznań. Economics \& Sociology 12(1):353-369

Tang Z, Ye Y, Jiang Z, Fu C, Huang R, Yao D (2020) A data-informed analytical approach to human-scale greenway planning: Integrating multi-sourced urban data with machine learning algorithms. Urban for Urban Green 56:126871

Wang W, Lin Z, Zhang L, Yu T, Ciren P, Zhu Y (2019) Building visual green index: a measure of visual green spaces for urban building. Urban for Urban Green 40:335-343
Wilson JS, Kelly CM, Schootman M, Baker EA, Banerjee A, Clennin M, Miller DK (2012) Assessing the built environment using omnidirectional imagery. Am J Prev Med 42(2):193-199

Wood S, Reynolds J (2012) Leveraging locational insights within retail store development? Assessing the use of location planners' knowledge in retail marketing. Geoforum 43(6):1076-1087. https://doi. org/10.1016/j.geoforum.2012.06.014

Ye Y, Richards D, Lu Y, Song X, Zhuang Y, Zeng W, Zhong T (2019) Measuring daily accessed street greenery: A human-scale approach for informing better urban planning practices. Landsc Urban Plann 191:103434

Zhang G, Zhang W, Guhathakurta S, Botchwey N (2019) Development of a flow-based planning support system based on open data for the City of Atlanta. Environ Plan B: Urban Analytics City Sci 46(2):207-224

Zhang F, Zhou B, Liu L, Liu Y, Fung HH, Lin H, Ratti C (2018) Measuring human perceptions of a large-scale urban region using machine learning. Landsc Urban Plan 180:148-160

Publisher's Note Springer Nature remains neutral with regard to jurisdictional claims in published maps and institutional affiliations. 